\title{
Physiological Monitoring of Cardiorespiratory Adaptations During ReHeARsal AND PerformanCE OF CoNTEMPorary DANCE
}

\author{
MATthew Wyon ${ }^{1}$ AND Emma ReDDing ${ }^{2}$ \\ ${ }^{1}$ School of Sport, Performing Arts and Leisure, University of Wolverhampton, United Kingdom; ${ }^{2}$ Laban, United \\ Kingdom.
}

\begin{abstract}
Wyon, M., and E. Redding. Physiological monitoring of cardiorespiratory adaptations during rehearsal and performance of contemporary dance. J. Strength Cond. Res. 19(3):000000. 2005.- Previous research has shown that dance class and rehearsal stress different cardiorespiratory energy systems than dance performance. The aim of the present study was to monitor the physiological parameters of a number of dancers during a 12-week rehearsal period and an 8-week performance schedule. Seventeen dancers ( 8 men and 9 women) from 2 companies undertook the multistage dance specific aerobic fitness test before the rehearsal period, before the performance period, and after the performance period. Heart rate data were collected throughout the test; the mean heart rate during stage 5 and blood lactate levels were measured at the end of the test. No significant changes in heart rate or lactate parameters were noted between the prerehearsal and preperformance tests, but significant decreases during the preperformance and postperformance tests were shown in both parameters $(p<0.01$ and $p<0.01$, respectively), which suggests an increase in the subjects' aerobic capacities during the performance period. Implications from the present study suggest that dancers are not adequately physiologically prepared to perform to the same degree to which their skills are honed. The study suggests that supplemental training is required to bridge this physical gap and better prepare the dancer for performance.
\end{abstract}

KEY WoRDs. energy systems, dance companies, performance preparation

\section{INTRODUCTION}

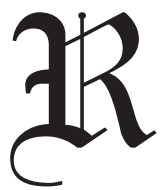

ist (17) has suggested that the gap between the physical demands of class and performance is widening. Wyon and Redding (22) later noted that dance performance caused a significantly greater mean heart rate and oxygen consumption than reported for dance class and rehearsal. The workload of the class warm-up section and most rehearsals is below the work intensity required to elicit an aerobic training effect (1). The mean workload of the class center section is similar to that seen during performances, but its exercise-to-rest ratio implies that the ATP-CP system receives the greatest stimulus during the work periods, whereas in performance the exercise-to-rest ratio allows greater emphasis on the aerobic and lactate metabolic systems (22). The findings of Wyon and Redding confer with previous research that shows that the center phase of a dance class is an intermittent "multiple sprint" form of exercise that does not place significant stress on the aerobic system $(4,6,16,19)$. The warm-up phase is more continuous in nature, although at too low an inten- sity to elicit a training effect. Dance performance can also be classified as high-intensity interval exercise $(5,19)$; the exercise intensity is similar to that of the center phase of the dance class, although the exercise-to-rest ratios differ and indicate that greater stress is placed on the aerobic energy system due to longer exercise and shorter rest periods $(21)$.

The aims of the present study were to examine whether the data reported in the cross-sectional analysis by Wyon and Redding (22) of the cardiorespiratory demands of individual classes, rehearsals, and performances validated the predicted cardiorespiratory changes in the dancers during an extended period that encompassed performance ( 8 weeks) and normal daily company routine (class or class and rehearsal; 12 weeks). Company 1 had cardiovascular training equipment for the dancers to use. The use of the equipment was not prescribed, and the dancers set their own programs if they used the equipment. The study also therefore assessed whether the provision of cardiovascular equipment was enough to help prepare dancers for the increased demands of performance.

\section{Methods}

\section{Subjects}

Twenty-two subjects from 2 professional contemporary dance companies volunteered for the study; their descriptive data are given in Table 1 . Company 1 promoted aerobic training for its dancers. This company had rowing and cycle ergometers and step machines for the dancers to use, but had made no time or guidance provision for the supplemental training. All the subjects from that company reported that they used these machines but not regularly. All subjects had been taking dance class on a regular basis for the preceding 1-2 weeks and were free of injury during this time. Anecdotal discussions noted that only 2 of the 22 subjects smoked. During the testing period, there was a dropout rate of $23 \%(n=5)$. The data from the subjects who left the study were excluded from the statistical analyses. The University of Surrey Roehampton gave ethical approval for the research. Written consent was gained from both the dancers and their respective companies before testing started.

\section{Protocol}

Descriptive data (age, height, and weight) were collected at the beginning of the study, and skinfold measurements 
TABLE 1. Descriptive statistics for the subjects.*

\begin{tabular}{cllcl}
\hline Company & \multicolumn{1}{c}{ Sex } & Age $(\mathrm{y})$ & Height $(\mathrm{cm})$ & Weight $(\mathrm{kg})$ \\
\hline 1 & Female $(n=6)$ & $23 \pm 5.57$ & $1.64 \pm 4.91$ & $51.7 \pm 3.79$ \\
& Male $(n=4)$ & $22 \pm 3.0$ & $1.77 \pm 3.40$ & $66.7 \pm 4.26$ \\
2 & Female $(n=3)$ & $23 \pm 1.73$ & $1.66 \pm 7.93$ & $55.7 \pm 3.51$ \\
& Male $(n=4)$ & $22 \pm 1.25$ & $1.76 \pm 5.71$ & $66.3 \pm 8.50$ \\
\hline
\end{tabular}

* Data are mean $\pm S D$.

TABLE 2. Mean parameter data for prerehearsal, preperformance, and postperformance tests.*

\begin{tabular}{clccc}
\hline Company & \multicolumn{1}{c}{ Test } & Mean HR $\left(\mathrm{b} \cdot \mathrm{min}^{-1}\right)$ & Maximum HR $(\%)$ & Blood lactate $\left(\mathrm{Mmol} \cdot \mathrm{L}^{-1}\right)$ \\
\hline \multirow{2}{*}{$(n=10)$} & Prerehearsal & $167 \pm 10.65$ & $84.7 \pm 4.89$ & $2.2 \pm 0.92$ \\
& Preperformance & $166 \pm 10.55$ & $84.1 \pm 4.99$ & $2.1 \pm 0.90$ \\
\multirow{2}{*}{$2(n=7)$} & Postperformance & $155 \pm 12.86$ & $77.9 \pm 6.18$ & $1.5 \pm 0.77$ \\
& Prerehearsal & $190 \pm 3.07$ & $96.3 \pm 1.96$ & $3.4 \pm 1.12$ \\
& Preperformance & $189 \pm 4.19$ & $95.8 \pm 2.23$ & $3.4 \pm 1.15$ \\
& Postperformance & $179 \pm 4.76$ & $91.8 \pm 3.17$ & $2.8 \pm 1.09$ \\
\hline
\end{tabular}

* Data are mean $\pm S D . \mathrm{Hr}=$ heart rate.

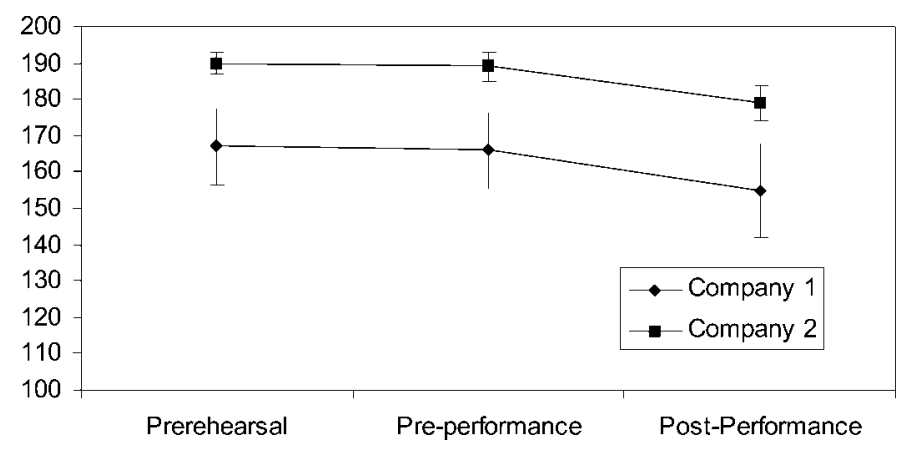

Figure 1. Changes in mean heart rate of dance specific aerobic fitness test stage 5 over time.

were taken before and after the performance period. Skinfold thickness measurements (in millimeters) were taken at 5 sites: biceps, triceps, suprailiac, subscapular, and medial calf.

The monitoring of cardiorespiratory changes was performed with the multistage dance aerobic fitness test (14). The test is continuous, with 5 steady-state stages of increasing intensity, each 4 minutes long. Before each test, each subject underwent a familiarization process and was introduced to the tempo of each stage by use of a metronome. Before the start of the test, the subjects were fitted with a Polar heart rate monitor and watch (Polar Accurrex). Each subject was informed of the test termination criteria (20) and that they would be given 2 warnings before being asked to stop dancing. The mean heart rate of the subject's last stage was calculated from the downloaded heart rate data. The mean heart rate of the last stage was calculated as a percentage of the subject's age-predicted maximum [(end heart rate/220 - age) $\times 100]$. A blood lactate sample was taken 1 minute after the test cessation using a Lactate-Pro following the British Association of Sport and Exercise Sciences procedures.

Each subject was tested 3 times during the testing period, at the same time of the day and generally on the same day of the week, but company timetables sometimes made this schedule impossible. The initial test was performed 1-2 weeks after the return from company break and $2-3$ weeks before the start of rehearsals. The second test occurred the week before the start of performing (week 12), each company being involved with a 2-month performance period, and was fitted in around the companies' schedules. The last test took place the week following the end of the respective tours (week 20). Feedback was provided to each of the subjects on their individual data.

\section{Statistical Analyses}

All data were entered into the SPSS version 10 statistical analysis software program (SPSS Inc, Chicago, IL). Means and $S D s$ were calculated for all variables. A repeated-measures analysis of variance (ANOVA) betweensubjects design, using difference contrasts, was used to monitor changes in mean heart rate, percentage of maximum heart rate, and blood lactate data collected during stage 5. The $\alpha$ level was set at 0.95 .

\section{RESUlts}

The repeated-measures ANOVA, using difference contrasts, compared prerehearsal with preperformance test results and pre- with postperformance test results. The descriptive statistics of the companies during the study period are given in Table 2. Groupwise analysis noted no significant differences between the prerehearsal and preperformance test results for mean heart rate $(p>0.05)$, percentage of maximum heart rate $(p<0.05)$, and blood lactate values $(p<0.05)$.

Significant decreases were found between the pre- and postperformance test results for mean heart rate $\left(\mathrm{F}_{1,12}=\right.$ 149.606; $p<0.01)$, maximum heart rate percent $\left(\mathrm{F}_{1,12}=\right.$ 40.878; $p<0.01)$, and blood lactate $\left(\mathrm{F}_{1,12}=12.093 ; p<\right.$ $0.01)$. Mean skinfold preperformance data $(36.35 \pm 9.74$ $\mathrm{mm}$ ) were not significantly different from the postperformance data $(35.54 \pm 9.68 \mathrm{~mm})(t=1.106, d f=13, p$ $=0.307)$. The changes in the companies' mean values can be seen in Figures 1-3. Between-subject analysis noted that company 1 had significantly lower data values than company 2 for mean heart rate $\left(\mathrm{F}_{1,12}=5653.926 ; p<\right.$ $0.01)$, maximum heart rate percent $\left(\mathrm{F}_{1,12}=6303.412 ; p<\right.$ $0.01)$, and blood lactate $\left(\mathrm{F}_{1,12}=98.166 ; p<0.01\right)$. 
WYON AND REDDING

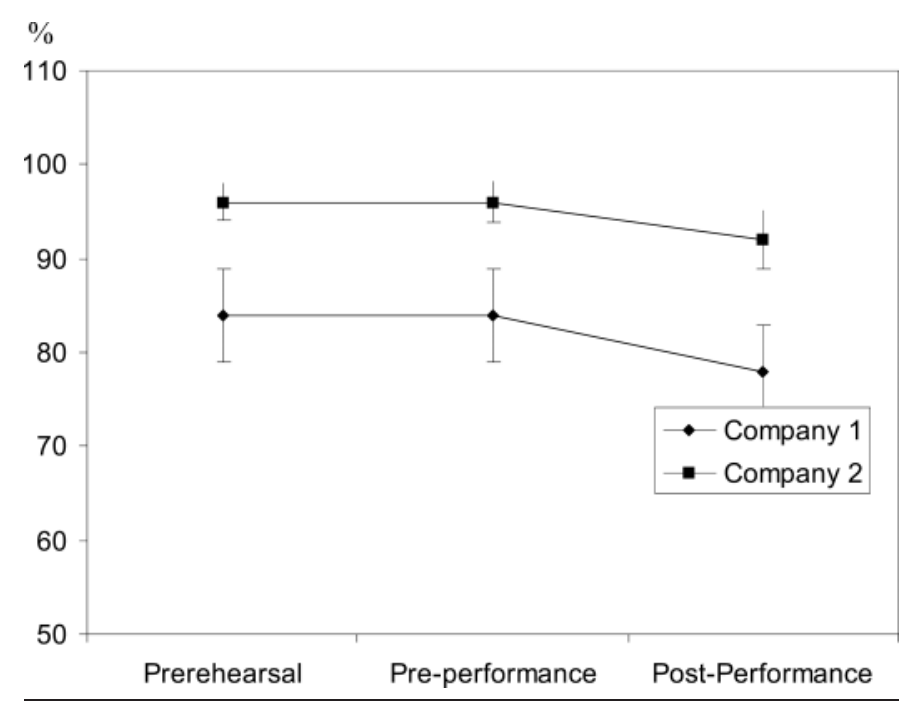

FIGURE 2. Changes in mean maximum heart rate percent of dance specific aerobic fitness test stage 5 over time.

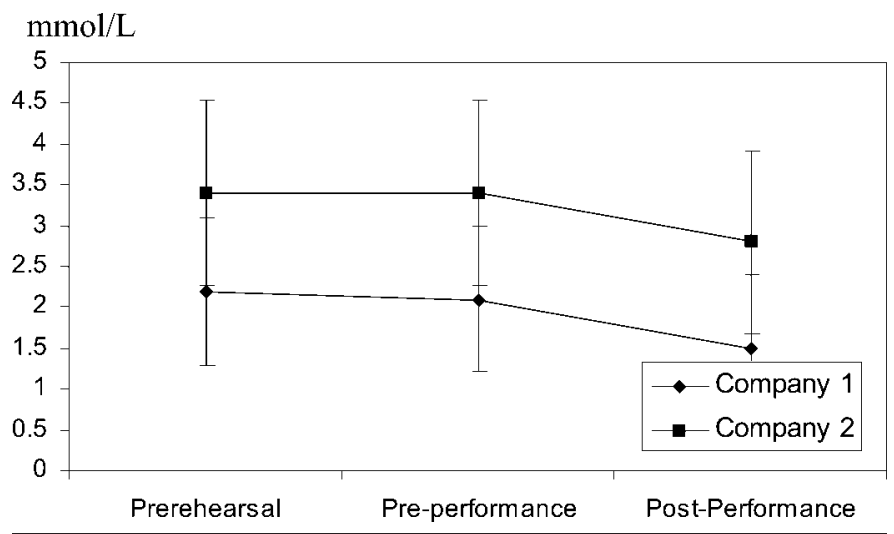

Figure 3. Changes in mean blood lactate values of dance specific aerobic fitness test stage 5 over time.

\section{Discussion}

The mean data given in Table 2 indicate that subjects from company 1 had greater aerobic capacities than those from company 2 , because their mean heart rates for stage 5 were at a lower relative percentage, in relationship to age-predicted maximum heart rate, than those for company 2 . This could be due to the availability and promotion of aerobic fitness by the management in company 1 . Neither company showed changes in aerobic fitness during the first period (prerehearsal to preperformance), as illustrated by heart rate and blood lactate data (Figures $1-3)$. The subjects in company 1 were able to complete the test at a lower relative workload than the company 2 subjects. This is illustrated by the lower blood lactate values shown in company 1 during the initial period. The lack of change in these parameters confirms the suggestions of Wyon and Redding (22), who hypothesized that the metabolic stresses placed on the dancer from class and rehearsal were not enough to develop the dancers' aerobic capacities. This phase of performance preparation is characterized by a daily class of approximately $90 \mathrm{~min}$ utes and rehearsal sessions that last between 60 and 180 minutes. The warm-up phase of class and most rehearsals are at a low exercise intensity, and only the center section of the dance class is at a high enough intensity to develop the aerobic system, although the exercise-to-rest ratio demonstrates that the actual exercise time is insufficient to stress the aerobic system enough for adaptation to occur. The exercise intensity of the rehearsal process increases to that seen within performance, but this is generally in the last week of rehearsals and too late to have a physiological benefit for the proceeding performance period. This is in contrast with findings by Rimmer et al. (16) and Dahlstrom et al. (6), who suggested that adequate time, during class and rehearsal, is spent within the aerobic training heart rate zones to stimulate a moderate aerobic training effect. The difference in findings could be due to differences in data analysis. They monitored heart rates during class and calculated time spent at specific heart rate bands. This does not take into account work-to-rest ratios; therefore, elevated heart rates from recovery periods were also included in the overall analysis. This would increase the supposed time spent within the aerobic training zone but not the actual exercise time within the zone, which is the stressor that causes adaptation (2)

The performance period is characterized by daily class (90 minutes), a short rehearsal (60-90 minutes), and the performance (approximately 60 minutes). During performance no dancer is on the stage all the time, although the exercise-to-rest ratio indicates more time dancing than resting. The performance period showed significant decreases in the heart rate parameters and blood lactate levels, indicating improvements of the subjects' aerobic capacities. This confirms the findings reported previously by Wyon and Redding, which indicated that the work intensities and exercise-to-rest ratios noted during performance were at a level to cause aerobic system adaptation. The amount of daily exercise that the individual performs decreases during the performance period, which would suggest that the main influence on any cardiorespiratory adaptations is due to changes in exercise intensity and the exercise-to-rest ratio. The results from the present study were also reinforced from the dancers, who commented that they felt it took 2 weeks of performing before they felt physically capable of "performing fully." The lack of change in skinfold measurements is not surprising due to the low levels of body fat of dancers $(3,12,13)$. Because of the lack of specified competitive periods or seasons as seen within the sporting world, which allows athletes to carry more fat during noncompetitive periods and then "strip-down" for competition, dancers often perform yearround, with only short periods off to rehearse the next piece. The culture and environment of the dance world also place pressure on the dancer to maintain low levels of body fat throughout the year, often to the detriment of their health $(3,7-12,15,17,18)$. The present study did not monitor other fitness components, such as power, strength, or muscular endurance, so one cannot comment on whether similar changes in these parameters might occur during the performance period as were seen for aerobic fitness. In conclusion, class and rehearsal did not prepare the dancers in this study adequately for the performance period. The provision of cardiovascular equipment, though beneficial, is not sufficient in itself, and the cardiorespiratory training needs to be planned and managed to the same extent as the rehearsal schedule to allow the dancers to peak for each performance period as physically as they do technically. 


\section{CARDiORESPIRATORY AdAPTATIONS IN DANCERS}

\section{Practical Applications}

The findings from the present study suggest the need to start applying training science within the dance world. Currently, the emphasis is mostly on the skill acquisition and perfection required to perform. The development of the dancer's physicality is thereby a by-product of the skill acquisition. An enhancement of the aerobic system is required, most likely at the prerehearsal stage, to allow the dancer the physiological capability to cope with the stresses during performance.

The use of heart rate monitors as the sole means of measuring time spent within specific training zones during current dance training exaggerates the actual training time. We suggest the use of TRIMPS (2) within an interval-based program as a means of monitoring the training effect of dance-based activity. The provision of cardiovascular equipment and a reliance on the dancer's motivation to perform self-administered training do not always provide adequate training stimuli to benefit the dancer during performance periods. Dance company management needs to schedule supplemental training into their timetables to reduce the potential onset of overtraining. We also suggest that these sessions are scheduled at the end of a dancer's training day so that fatigue does not affect skills-based sessions (rehearsals) and allows the dancer an extended period to warm down without the need to rush off for the next rehearsal.

\section{REFERENCES}

1. BALADY, G.J., et al. ACSM's Guidelines for Exercise Testing and Prescription. 6th ed. B.A. Franklin, M.H. Whaley, and E.T. Howley, eds. Philadelphia: Lippincott Williams \& Wilkins, 2000.

2. BANISTER, E. Modeling athletic performance. In: Physiological Testing of the High Performance Athlete. H.J. Green, ed. Chicago: Human Kinetics, 1991. pp. 403-424.

3. BRinson AND F. Dick. Fit to Dance? London: Calouste Gulbenkian Foundation, 1996.

4. CoHEn, J.L., et al. Cardiorespiratory responses to ballet exercise and $\mathrm{Vo}_{2 \max }$ of elite ballet dancers. Med. Sci. Sport Exerc. 14:212-217. 1982.

5. Cohen, J.L., K.R. Segal, And W.D. McArdle. Heart rate response to ballet stage performance. Physician Sportsmedicine 10:120-133. 1982.
6. Dahlstrom, M., et al. Physical fitness and physical effort in dancers: a comparison of four major dance styles. Impulse 4: 193-209. 1996.

7. Hamilton, L.H., et al. The role of selectivity in the pathogenesis of eating problems in ballet dancers. Med. Sci. Sport Exerc. 20:560-565. 1988.

8. Hamilton, L.H., et al. Personality, stress and injuries in professional ballet dancers. Am. J. Sports Med. 17:263-267. 1989.

9. Hamilton, W.G. Physical prerequisites for ballet dancers. $J$. Musculoskel. Med. November:61-67. 1986.

10. Holderness, C.C., J. Brooks-GunN, AND M.P. WarRen. Eating disorders and substance use: A dancing vs a nondancing population. Med. Sci. Sport Exerc. 26:297-302. 1994.

11. Keay, N., I. Fogelman, AND G. Blake. Bone mineral density in professional female dancers. Br. J. Sports Med. 31:143-147. 1997.

12. KoUteDAKIS, Y., et al. The effects of rest and subsequent training on selected physiological parameters in professional female classical dancers. Int. J. Sports Med. 20:379-383. 1999.

13. Koutedakis, Y., AND N.C.C. SHARP. The Fit and Healthy Dancer. Chichester: John Wiley and Sons, 1999.

14. REDDING, E., et al. Validity of using heart rate as a predictor of oxygen consumption in dance. J. Dance Med. Sci. 2003.

15. RIEL, K.A., AND P. BERNETT. Dance typical injuries and overuse syndromes. Deutsche Zeitschrift sportmedizin 44(7). 1993.

16. Rimmer, J.H., D. JAY, AND S.A. Plowman. Physiological characteristics of trained dancers and intensity level of ballet class and rehearsal. Impulse 2:97-105. 1994.

17. Rist, R.-A. Children and exercise: Training young dancers, a dance medicine perspective. Sportcare J. 1(6):5-7. 1994.

18. SANDRI, S.C. On dancers and diet. Int. J. Sport Nutr. 3:334342. 1993.

19. Schantz, P.G., AND P.-O. Astrand. Physiological characteristics of classical ballet. Med. Sci. Sport Exerc. 16:472-476. 1984.

20. Wyon, M., et al. Reliability and validity of a multistage dance specific aerobic fitness test (DAFT). J. Dance Med. Sci. 7(2). 2003.

21. Wyon, M.A., et al. Oxygen uptake during of modern dance class, rehearsal and performance. J. Strength Cond. Res. In press.

22. Wyon, M.A., AND E. REDDING. The physiological monitoring of cardiorespiratory adaptations during rehearsal and performance of contemporary dance. J. Strength Cond. Res. In press.

Address correspondence to Mr. Matthew Wyon, m.wyon@wlv.ac.uk. 